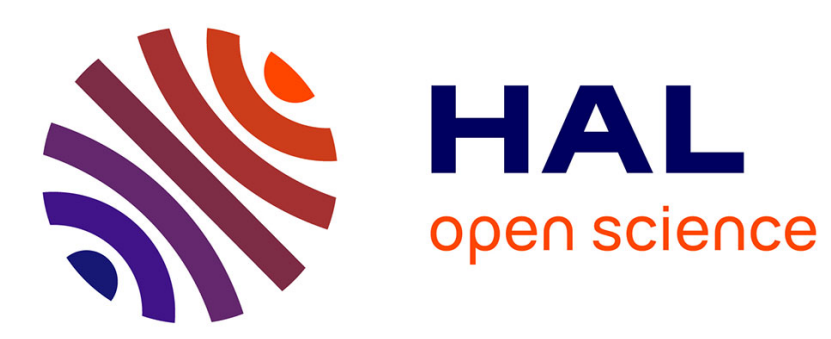

\title{
Size-Dependent Structural, Energetic, and Spectroscopic Properties of MoS 3 Polymorphs
}

\author{
Amit Sahu, Stephan Steinmann, Pascal Raybaud
}

\section{To cite this version:}

Amit Sahu, Stephan Steinmann, Pascal Raybaud. Size-Dependent Structural, Energetic, and Spectroscopic Properties of MoS 3 Polymorphs. Crystal Growth \& Design, 2020, 20 (12), pp.7750-7760. 10.1021/acs.cgd.0c00981 . hal-03120168

\section{HAL Id: hal-03120168 \\ https://hal-ifp.archives-ouvertes.fr/hal-03120168}

Submitted on 25 Jan 2021

HAL is a multi-disciplinary open access archive for the deposit and dissemination of scientific research documents, whether they are published or not. The documents may come from teaching and research institutions in France or abroad, or from public or private research centers.
L'archive ouverte pluridisciplinaire HAL, est destinée au dépôt et à la diffusion de documents scientifiques de niveau recherche, publiés ou non, émanant des établissements d'enseignement et de recherche français ou étrangers, des laboratoires publics ou privés. 


\title{
Size dependent structural, energetic and spectroscopic properties of the $\mathrm{MoS}_{3}$ polymorphs
}

\author{
$\underline{\text { Amit Sahu }}^{1,2}$, Stephan N. Steinmann ${ }^{2}$ and Pascal Raybaud ${ }^{1,2 *}$ \\ ${ }^{1}$ IFP Energies Nouvelles, Rond-point de l'échangeur de Solaize, $\mathrm{BP}_{3}$ - Solaize 6936o (France) \\ ${ }^{2}$ Univ Lyon, ENS de Lyon, CNRS UMR 5182, Laboratoire de Chimie, 69342 (France)
}

\begin{abstract}
In spite of the attractive interest of a-MoS 3 based nanomaterials, the amorphous nature of the MoS $\mathrm{phase}_{3}$ makes it challenging to control and understand its chemical reactivity. In particular, the type of the structural building unit such as $\mathrm{Mo}_{3}$ triangular vs. Mo chain is still debated, while the ambivalent interpretation of the nature of sulfur species $\left(\mathrm{S}^{2-}, \mathrm{S}_{2}{ }^{2-}\right)$ and Mo-Mo bonds leads to ambiguous interpretations of spectroscopic data and reactivity. By density functional theory (DFT), we simulate the energetic, structural, and spectroscopic features of relevant oD-, $1 \mathrm{D}-$ and $2 \mathrm{D}-\mathrm{MoS}_{3}$ triangular, chain-like polymorphs, including unprecedented ones (ring, wave and helix) and revisit the interpretation of EXAFS, IR-RAMAN, and XPS experimental data. We analyze how $\mathrm{Mo}_{\mathrm{k}} \mathrm{S}_{3 \mathrm{k}}$ clusters of a few $k$ atoms may grow up to infinite $\mathrm{MoS}_{3}$ polymorphs (periodic replica). The evolution of the growth energy and the computed IR spectra within density functional perturbation theory level suggest the coexistence of various polymorphs in the $\mathrm{MoS}_{3}$ phase as a function of sizes. Molecular dynamics simulations reveal how the small triangular $\mathrm{Mo}_{\mathrm{k}} \mathrm{S}_{3 \mathrm{k}}$ oligomers may transform into a more condensed $\mathrm{MoS}_{3}$ patches resembling embryos of the $2 \mathrm{D} 1 \mathrm{~T}^{\prime}-\mathrm{MoS}_{2}$ phase. Finally, we discuss some plausible transformation pathways from one polymorph to another.
\end{abstract}

KEYWORDS: $\mathrm{MoS}_{3}$ polytypes, $\mathrm{MoS}_{2}$, density functional theory, Infra-Red, Thermochemistry, Growth

\section{INTRODUCTION}

Over the past few decades, amorphous $\operatorname{MoS}_{3}\left(a-\mathrm{MoS}_{3}\right)$ based nanomaterials have gained great attention from the scientific community because of their versatile properties valuable for industrial applications as well as for numerous emerging applications in new energies. The $a-\mathrm{MoS}_{3}$ phase was shown to play a key role as electro-and photochemical (pre-)catalysts for hydrogen evolution reaction (HER) ${ }^{1-3}$ It was also found to exhibit attractive capacity and rate capability when used in electrodes materials for batteries. $^{4-8}$ The use of $a-\mathrm{MoS}_{3}$ was also suggested to improve the recovery of $\mathrm{Hg}$ capture from flue gas. ${ }^{9,10}$ Finally, in the synthesis of industrial $\mathrm{MoS}_{2}$ based catalysts used in hydrodesulfurization (HDS), $a-\mathrm{MoS}_{3}$ is known to be a key precursor formed during the activation of the $2 \mathrm{H}-\mathrm{MoS}_{2}$ nano-crystalline phase. ${ }^{11,12}$

Many of these interesting properties of $a-\mathrm{MoS}_{3}$ are supposed to originate from its intriguing amorphous $1 \mathrm{D}$ - or 2D-nano-structure where Mo atoms are interconnected by various types of sulfur atoms such as $\mathrm{S}^{2-}$ and $\mathrm{S}_{2}{ }^{2-}$ species. These versatile species are suspected to improve the reactivity towards the different key reactants involved in the targeted applications: diffusion of cations in battery materials ${ }^{6,7}$, activation of $\mathrm{H}_{2}$ in $\mathrm{HER}^{13-16}$ and HDS reaction $^{17}$, and specific interaction with Hg. ${ }^{9}$

Nevertheless, in spite of these wide range of potential applications of $\mathrm{MoS}_{3}$, challenging questions remain open regarding its structural, electronic, and spectroscopic features. Indeed, the amorphous nature of $\mathrm{MoS}_{3}$ makes it difficult to precisely identify the type and local structure of these active sulfur sites in order to better rationalize their reactivity.

Since the early 7o' several experimental studies were devoted to the a-MoS 3 phase. ${ }^{18-33}$ However, the atomistic picture of a-MoS ${ }_{3}$ remains uncertain. In particular, there is historical and still vivid debate on the nature of the structural building block, either $\mathrm{Mo}_{3}$ triangular ${ }^{27,34,35}$ or Mo chain-like, ${ }^{19,23,28,29}$ and the oxidation states of Mo atoms which also depends on the characterization techniques used.

Earlier studies based on radial distribution function (RDF), extended X-ray absorption spectroscopy (EXAFS), magnetic susceptibility and X-ray photoelectron spectroscopy (XPS) proposed a chain-like model along with the Mo oxidation state five. ${ }^{19,23}$ EXAFS data suggested that two types of Mo-Mo bonds would be present in $a-\mathrm{MoS}_{3}$ : one short bond at $2.74 \AA$ and one long at $3.14 \AA$. $^{1921}$ So every metal atoms would be involved in a Mo-Mo pair generating alternatively short Mo-Mo bond, and longer Mo-Mo bond connecting each dimer. However, many subsequent EXAFS studies identified only one short MoMo bond at $2.75^{-2} .77 \AA .^{28,31,33,36}$ Based on an extensive EXAFS study, Cramer et al. proposed two possible models a chain-like and cyclic $\mathrm{Mo}_{3}$ model with two possible oxidation states $\mathrm{Mo}^{5+}\left(\mathrm{S}^{2-}\right)_{2}\left(\mathrm{~S}_{2}{ }^{2-}\right)_{1 / 2}$ and $\mathrm{Mo}^{4+}\left(\mathrm{S}^{2-}\right)\left(\mathrm{S}_{2}{ }^{2-}\right)$ respectively, admitting that they cannot be distinguished by EXAFS. ${ }^{36}$ By combining low angle X-ray diffraction (XRD) and theoretical models, Chien et al. preferentially suggested a $\mathrm{Mo}^{5+}$ chain like model with two Mo-Mo bonds: one short at $2.80 \AA$ and a very long one at $3.40 \AA .^{23}$ 
A combined neutron diffraction study and reverse Monte Carlo simulation method study by Hibble et al. ${ }^{37}$ contradicted the previous studies by proposing a chain like model of $\mathrm{Mo}^{4+}\left(\mathrm{S}^{2-}\right)\left(\mathrm{S}_{2}{ }^{2-}\right)$ with only one short Mo-Mo distance. This result was consistent with earlier XPS emission and absorption studies analyzing the nature of the covalent nature of chemical bonding in $\mathrm{MoS}_{3}$ and concluding that Mo with formal oxidation state of +4 was more plausible. ${ }^{38}$

IR and Raman investigations on a-MoS 3 and poorly crystalline $\mathrm{MoS}_{2}$ provided other interesting insights into the features of $\mathrm{MoS}_{3}$ phase. ${ }^{20}$ The characteristic peak at 522 $\mathrm{cm}^{-1}$ was assigned to S-S stretching present in $\mathrm{MoS}_{3}$. Based on XPS and IR analyses, Weber et al. proposed a triangular model inspired by $\mathrm{Mo}_{3}$ clusters also argued that Mo has +4 formal oxidation state and identified the presence of various $\mathrm{S}$ species such as $\mathrm{S}^{2-}$ and $\mathrm{S}_{2}{ }^{2-}$ ligands. By IR analysis, the main observed bands at 545, 520 and $470 \mathrm{~cm}$ ${ }^{1}$ were assigned to $(\mathrm{S}-\mathrm{S})_{\mathrm{br}},(\mathrm{S}-\mathrm{S})_{\mathrm{t}}$ and $(\mathrm{Mo}-\mathrm{S})_{\mathrm{ap}}$ on the basis of a $\left(\mathrm{NH}_{4}^{+}\right)_{2}\left[\mathrm{Mo}_{3} \mathrm{~S}_{13}{ }^{2-}\right]$ reference compound. This interpretation must be taken with care due to charge and overstoichiometry of $\left[\mathrm{Mo}_{3} \mathrm{~S}_{13}\right]^{2-}$ as we will discuss below. ${ }^{27}$

Within the context of HER, Tran et al. ${ }^{3}$ provided recently for the first time high resolution HAADF-STEM images of the $\mathrm{MoS}_{3}$ structures highly dispersed on carbon materials. This analysis suggested that there would be an oligomeric arrangement of triangular $\mathrm{Mo}_{3}$ cluster units in a onedimensional quasi-linear or branched chain. ${ }^{3}$

Most experimental investigations which attempted to rationalize their observation refer either to the linear or triangular building blocks without clear justification. At the same time, there exists very few theoretical studies devoted to the structural resolution and most of the existing ones also assumed one type of structure. Considering quantum simulation dedicated on the $\mathrm{MoS}_{3}$ structure, Jiao et al. ${ }^{35}$ simulated four possible triangular $\mathrm{Mo}_{3} \mathrm{~S}_{9}$ structures as empirically proposed earlier by Weber et al. ${ }^{27}$ It was found in particular that the most stable structures significantly reconstruct from the initial structure proposed by Weber et al., while the corresponding formal oxidation state of Mo shifts from +4 to +4.67 . In the lowest energy structures, short and long Mo-Mo distances are close to EXAFS data. However, due to the strong distortion of the clusters, it is difficult to compare the calculated vibrational frequencies with the experimental IR spectrum. ${ }^{35}$ Other quantum simulations investigating the reactivity of the $\mathrm{MoS}_{3}$ phase assumed a $\mathrm{Mo}_{3}$ triangular model, without clear justification of it. ${ }^{39,40}$

As a consequence, there is a clear lack of accurate atomic scale's insights into the structural and spectroscopic properties of the a-MoS 3 phase. Density functional theory (DFT) provides a powerful formalism to revisit the empirical proposals formulated since the 7o's.

In this work, by means of DFT calculations, we will investigate the previously proposed chain-like or triangular structures of $\mathrm{MoS}_{3}$. Moreover, we will also shed light on some unprecedented oD-2D-nano-structures of the $\mathrm{MoS}_{3}$ polymorphs. To validate the reliability of the newly proposed structures, we will analyze first the various structures and compare them with available EXAFS data. Then, the relative stability of the various polymorphs will be determined as a function of sizes. Thirdly, we will simulate IR spectra of these models by density functional perturbation theory (DFPT) approach and compare them with a reference experimental IR spectrum of bulk-MoS ${ }_{3}{ }^{27}$ After a brief discussion of the corresponding XPS signals, we finally propose the possible transformation of $\mathrm{MoS}_{3}$ polymorphs upon oligomerization.

\section{COMPUTATIONAL METHODS}

For all the calculation, density functional theory (DFT) as implemented in VASP $^{4-43}$ has been used relying on the Perdew-Burke-Ernzerhof (PBE) $)^{44}$ functional within the framework of generalized gradient approximation (GGA). The long-range interactions were included through a density-dependent dispersion correction $(\mathrm{dDsC})^{45,46}$. The projector augmented-wave (PAW) method ${ }^{47}$ was chosen to describe the electron-ion interaction. The kinetic energy cut-off for the plane-wave basis set has been fixed at $500 \mathrm{eV}$. Furthermore, for the minimization of the electronic energy, a Gaussian smearing with a width of $0.2 \mathrm{eV}$ was chosen, while a mixture of the blocked-Davidson scheme and residual minimization method direct inversion in the iterative subspace has been applied. Spinpolarized calculations were performed to obtain the ground state of the clusters. Brillouin zone integration has been adapted as a function of each simulated system either cluster or periodic structure.

To represent the $\mathrm{MoS}_{3}$ polymorphs, we simulated two types of molecular models: $\mathrm{Mo}_{\mathrm{k}} \mathrm{S}_{3 \mathrm{k}}$ clusters of various finite sizes and periodic structures of infinite size in one dimension. A large vaccume has been used, to minimize the spurious interections with neighboring images, along the nonperiodic directions of the respective models. To optimize the structures of the various polymorphs, the conjugate gradient algorithm was used. Electronic and geometric convergence cut-off has been set to $10^{-6} \mathrm{eV}$ and $0.02 \mathrm{eV} / \AA ̊$, respectively. For the clusters' geometry optimization, a large cubic supercell was used to avoid the spurious interactions of the clusters with its periodic images. For the periodic structures, the ionic positions and cell parameter along the periodic replica have been optimized.

The exploration of some complex structures has been refined by ab initio molecular dynamics (AIMD) with the scaled velocity Verlet algorithm to solve Newton's equations of motions (time step of $5 \mathrm{fs}$ and $\mathrm{T}=1000 \mathrm{~K}$ ).

For frequency calculations, the structures have been optimized with tighter convergence criteria such as $10^{-7} \mathrm{eV}$ for electronic properties and $0.01 \mathrm{eV} / \AA ̊$ for geometry. To calculate the frequencies and corresponding infra-red intensities, the linear response method with density func- 
tional perturbation theory (DFPT) has been used as implemented in VASP. ${ }^{4}$ We convoluted the IR intensity peaks by normal distribution with the variance $80 \mathrm{~cm}^{-1}$ to compare with the experimental IR.

To calculate the core-level binding energy $(\triangle \mathrm{BE})$, we use Janak-Slater transition state approach ${ }^{49-51}$, where half electron is shifted to the lowest unoccupied molecular orbital (LUMO) from its core rather than creating a full core-hole. We compare this $\triangle \mathrm{BE}$ with available XPS data.

For determining the thermodynamic stability of the various oligomers, the following equation has been used to calculate the relative growth energy $\Delta E$ at o K:

$M o_{3} S_{9} \rightarrow \frac{3}{k} M o_{k} S_{3 k}$

$\Delta E=\frac{3}{k}\left[E\left(M o_{k} S_{3 k}\right)-E\left(M o_{3} S_{9}\right)\right]$

where $E\left(M o_{k} S_{3 k}\right)$ is the electronic energy of the $\mathrm{Mo}_{\mathrm{k}} \mathrm{S}_{3 \mathrm{k}}$ cluster or periodic structure, and $E\left(\mathrm{Mo}_{3} \mathrm{~S}_{9}\right)$ is the energy of $\mathrm{Mo}_{3} \mathrm{~S}_{9}$ cluster used as a reference. The effect of zeropoint energy, thermal corrections, and entropy, have be included to calculate the free energy variation (details are given in Supporting information SI.3) :

$\Delta G=\frac{3}{k}\left[G_{v i b}\left(M o_{k} S_{3 k}\right)-G_{v i b}\left(M o_{3} S_{9}\right)\right]$

We have assumed that the $\mathrm{Mo}_{\mathrm{k}} \mathrm{S}_{3 \mathrm{k}}$ clusters or infinite structures are immobile, and thus they have no translational and rotational contributions.

\section{RESULTS}

\section{Structure Analysis}

oD- and $1 \mathrm{D}$-model of triangular oligomers (TO). Inspired by the earlier experimental work by Weber et al. ${ }^{27}$, we first optimized the numerous possible structures of the $\mathrm{Mo}_{3} \mathrm{~S}_{9}$ triangular monomers. All these structures differ by the nature, number and location of sulfur species:

- $\mathrm{S}_{2}{ }^{2-}$ dimers, either on top (also called $\mu_{1}-S_{2}$ in what follows) or in bridging site $\left(\mu_{2}-S_{2}\right)$,

- $S^{2-}$ atoms, either on top $\left(\mu_{1}-S\right)$, or in the bridging site $\left(\mu_{2}-S\right)$ or in the hollow site $\left(\mu_{3}-S\right)$.

The most stable structure is shown in Figure $1 \mathrm{a}$ ), while other metastable structures with relative energies are given in Figure $\mathrm{S}$. This stable structure exhibits :

- two $S_{2}{ }^{2-}$ dimers : one $\mu_{1}-S_{2}$ and one $\mu_{2}-S_{2}$,

- four $S^{2-}$ atoms : two $\mu_{1}-S$, two $\mu_{2}-S$ and one $\mu_{3}-S$.

None of the empirically proposed structures by Weber et al. ${ }^{27}$ corresponds to the most stable one: their energy is at least $+0.65 \mathrm{eV}$ higher than the one reported in Figure $1 \mathrm{a}$ ). Weber's proposals were made on the assumption of the experimentally observed +4 oxidation state of Mo. Actually, our minimal energy structure of $\mathrm{Mo}_{3} \mathrm{~S}_{9}$ exhibits an average formal oxidation state of +4.67 (assuming a formal $2 \mathrm{e}^{-}$charge for the $\mathrm{S}$-atom and $\mathrm{S}_{2}$ dimers). Previous
DFT calculations also showed that Weber's structures are subject to strong reconstructions, and the resulting Mo exhibits formal oxidation states higher than $+4 .{ }^{35}$ This apparent discrepancy indicates that such $\mathrm{Mo}_{3} \mathrm{~S}_{9}$ triangular monomers are not the dominant species in a-MoS 3 . Nevertheless, they might co-exist with other oligomeric structures with an average oxidation state close to +4 .

Triangular oligomers (TO) (a)

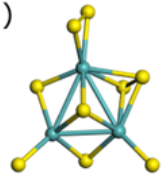

$\mathrm{Mo}_{3} \mathrm{~S}_{9}$

(c) Open-ring (OR)

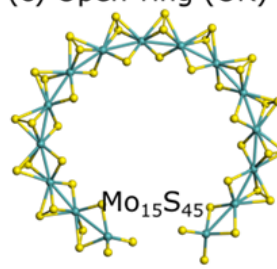

(e) Ring (R)

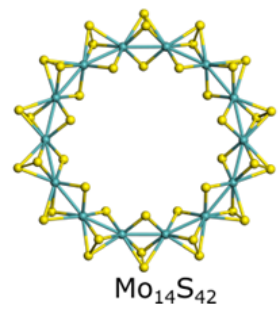

(b)

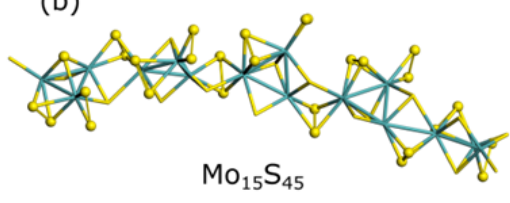

(d) Wave-like (WL)

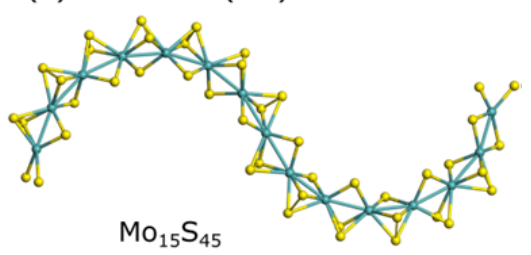

(f) $1 \mathrm{~T}^{\prime}-\mathrm{MoS}_{3}$

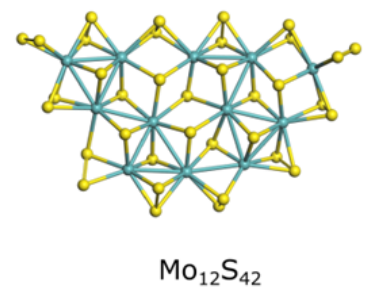

Figure 1 (a) Various oD-MoS3 nano-structures: Triangular monomer $\mathrm{Mo}_{3} \mathrm{~S}_{9}$ and triangular oligomers (TO) $\mathrm{Mo}_{15} \mathrm{~S}_{45}$, (c) open ring (OR) conformer, (d) Wave like (WL), (e) Ring (R) and (f) $1 \mathrm{~T}^{\prime}-\mathrm{MoS}_{3}$ (see text for explanation).

Interestingly, our most stable $\mathrm{Mo}_{3} \mathrm{~S}_{9}$ structure exhibits two distinct types of Mo-Mo bond length: one short MoMo bond at 2.72 $\AA$ and two long Mo-Mo bonds at $2.96 \AA$ which are compatible with some experimental EXAFS studies: 2.75 and $3.16 \AA$, respectively, ${ }^{19,36}$ although we noticed a slight underestimation of $0.18 \AA$ for the long MoMo bond. Also, the mean Mo-S bond length (2.35 $\AA$ ) is in close agreement with the experimental value $(2.41 \AA)$.

However, as suggested experimentally, $a-\mathrm{MoS}_{3}$ could actually consist of larger oligomers made of $\mathrm{Mo}_{3} \mathrm{~S}_{9}$ triangular clusters interconnected by $\mathrm{S}$ species. ${ }^{3,27}$ Exploring the size effects on triangular oligomers (TO) requires the simulations of various TO conformers. For $\mathrm{Mo}_{6} \mathrm{~S}_{18}$ this revealed that the interconnection of two $\mathrm{Mo}_{3} \mathrm{~S}_{9}$ triangular units occurs through one $S_{2}$ dimer and one $S$ atom (initially $\mu_{2}-S$ ) becoming $\mu_{3}-S$ (Figure $S_{2}$ ). Hence, this interconnection does not involve only one or two S-atoms as initially suggested, ${ }^{27}$ but three S-atoms. This structural trend is further confirmed for the larger oligomers $\mathrm{Mo}_{9} \mathrm{~S}_{27}$, 
$\mathrm{Mo}_{12} \mathrm{~S}_{36}$ and $\mathrm{Mo}_{15} \mathrm{~S}_{45}$ (Figure $\mathrm{S}_{3}-\mathrm{a}$ and Figure $1 \mathrm{~b}$ ). The average formal oxidation state of $\mathrm{Mo}$ in these oligomeric structures continuously decreases from +4.67 for $\mathrm{Mo}_{3} \mathrm{~S}_{9}$ to +4.16 for $\mathrm{Mo}_{15} \mathrm{~S}_{45}$ TO. This evolution is due to the vanishing contribution of $\mu_{1}-S_{1}$ species located at edges when size increases. Note that in the following, we will call "edges" the two terminal units of the chain like model.

To go beyond the oD structures, we have optimized the corresponding $1 \mathrm{D}$ structure of $\mathrm{TO}$ systems. According to the spatial rotation of each $\mathrm{Mo}_{3} \mathrm{~S}_{9}$ triangular unit along the TO chain, the smallest periodic structure allowing the chain interconnection between two neighboring supercells was found for $\mathrm{Mo}_{18} \mathrm{~S}_{54}$ (Table $\mathrm{S}_{2}$ and Figure $2 \mathrm{a}$ ). For this $1 \mathrm{D}$ TO-periodic (TO-P) chain, no $\mu_{1}-\mathrm{S}$ species remains as a consequence of periodicity. Moreover, the mean Mo oxidation state reaches the limit of +4 for TO-P, while it is 4.11 for $\mathrm{Mo}_{18} \mathrm{~S}_{54}$, both of which are very close to the experimental value. ${ }^{27}$

Considering the local interatomic distances, the short and long Mo-Mo and Mo-S bond-lengths slightly expand as a function of the oligomer size (Table S2). For the $\mathrm{Mo}_{18} \mathrm{~S}_{54}$ TO-P structure, we determine these bond lengths (Table 1) by calculating the pair correlation functions (PCF, Figure S8). The short Mo-Mo bond length is about $2.76 \AA$, and the long Mo-Mo bond becomes $3.08 \AA$ which is in closer agreement with the experimental EXAFS data (Table 1).${ }^{19}$ As the size of TO increases, the long Mo-Mo bond present in triangular monomers such as $\mathrm{Mo}_{3} \mathrm{~S}_{9}$ shortens (Figure $\mathrm{S}_{4} \mathrm{a}$ ) while the long Mo-Mo bond is located at the interconnection of two triangular monomers along the chain. The mean Mo-S bond length also slightly expands to $2.42 \AA$ with the size increase, in good agreement with EXAFS.

At this stage, we must recall that many EXAFS studies do not report the long Mo-Mo bond length ${ }^{28}$ which may raise question about the precise assignment of the structure on the basis of the Mo-Mo distance. Therefore, we also investigate alternative structures below.

oD and $1 \mathrm{D}$-Chain like models: open-ring (OR), wavelike (WL), linear (L) and helical (HL). Within the chain-like models, two competing ones were initially proposed: one strictly linear made of $\mathrm{Mo}^{5+}\left(\mathrm{S}^{2-}\right)_{2}\left(\mathrm{~S}_{2}{ }^{2-}\right)_{1 / 2}{ }^{19,23}$ and one distorted made of $\mathrm{Mo}^{4+}\left(\mathrm{S}^{2-}\right)\left(\mathrm{S}_{2}{ }^{2-}\right) .{ }^{37}$ Hence, we started by investigating two periodic structures of strictly linear chain like models involving either $\mathrm{Mo}^{5+}\left(\mathrm{S}^{2-}\right)_{2}\left(\mathrm{~S}_{2}{ }^{2-}\right)_{1 / 2}$ or $\mathrm{Mo}^{4+}\left(\mathrm{S}^{2-}\right)\left(\mathrm{S}_{2}{ }^{2-}\right)$. For the $\mathrm{Mo}^{5+}$ model, the optimized structure (Figure $\mathrm{S}_{7} \mathrm{~b}$ ) confirm the presence of two MoMo bond lengths (2.70 and 3.28 $\AA$ ) compatible with Ref. ${ }^{23}$ while for the $\mathrm{Mo}^{4+}$ model (Figure $2 \mathrm{~b}$ ), the structure exhibit one short Mo-Mo bond only (2.90 Å) longer than the one usually reported by EXAFS (Table 1$).{ }^{28}$ Moreover, the DFT energies show that the $\mathrm{Mo}^{4+}$ model is more stable by o.11 eV per $\mathrm{MoS}_{3}$ unit. This preliminary result may be consistent with Hibble's proposal. ${ }^{37}$

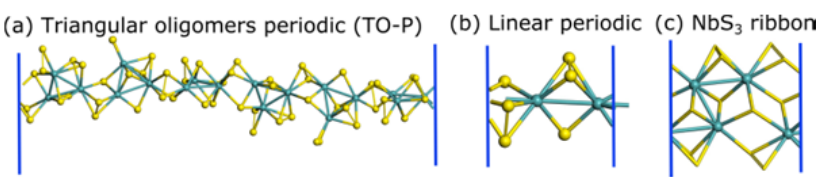

(d) Wave periodic (WL-P)

(e) Helical periodic (HL-P)

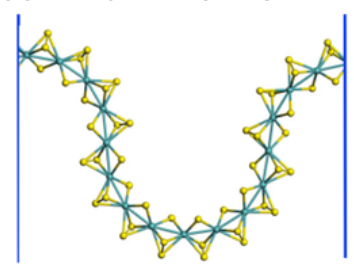

Figure 2 : Various $\mathrm{MoS}_{3}$ nanostructures : a) Triangular oligomers $\mathrm{Mo}_{18} \mathrm{~S}_{54}$ (TO-P), (b) Linear periodic $\mathrm{Mo}_{2} \mathrm{~S}_{6}$ (L-P), (c) $\mathrm{NbS}_{3}$-ribbon $\left(\mathrm{Mo}_{4} \mathrm{~S}_{12}\right)$ (d) $\mathrm{Mo}_{16} \mathrm{~S}_{48}$ Wave-like (WL-P), and (e) $\mathrm{Mo}_{17} \mathrm{~S}_{51}$ Helical (HL-P). Direction perpendicular to the blue lines is the direction of periodicity.

Releasing the periodic constraint, any attempt to stabilize a finite size $\mathrm{Mo}_{\mathrm{k}} \mathrm{S}_{3 \mathrm{k}}$ clusters of $\mathrm{Mo}^{5+}\left(\mathrm{S}^{2-}\right)_{2}\left(\mathrm{~S}_{2}{ }^{2-}\right)_{1 / 2}$ formal unit relaxed into a curved chains of $\mathrm{Mo}^{4+}\left(\mathrm{S}^{2-}\right)\left(\mathrm{S}_{2}{ }^{2-}\right)$ : open-ring (OR, Figures $1 \mathrm{c}$ and $\mathrm{S}_{3} \mathrm{~b}$ ) and wave-like (WL, Figures $1 \mathrm{~d}$ and $S_{3}$ c). The observed curvatures are induced by the relative position of two successive $\mathrm{S}_{2}$ dimers. In OR, the relative tilting angle of two successive dimers is always $\sim 60^{\circ}$ (Figure $\mathrm{S}_{5}$ ). When this alternate tilting of two successive $S_{2}$ dimers is locally broken at a chain's point, the chain curvature changes which leads to a WL-type structure (Figure $1 \mathrm{~d}$ ). In the extreme case of a linear chain, the relative tilting angle between two successive dimers is $\sim 90^{\circ}$ (Figure $\mathrm{S}_{5}$ ).

As for TO polymorphs and linear chain, we explore the construction of $1 \mathrm{D}$-periodic structures for the curved structures. One original structure directly inherited from $\mathrm{OR}$, is the closed ring $(\mathrm{R})$ represented for $\mathrm{Mo}_{14} \mathrm{~S}_{42}$ in Figure $1 \mathrm{e}$, which resembles $\mathrm{MoS}_{2}$ nanotubes. ${ }^{52}$ In that case, OR is locked by bridging the two edges through Mo-S-Mo bonds involving the dangling $\mathrm{S}$ and $\mathrm{S}_{2}$ species at OR edges. Nevertheless, this lock of the cycle only occurs for an even number of Mo atoms because of the tilting alternation of the $\mathrm{S}_{2}$ dimer invoked before. The cycle tension depends on the size and, hence, the relative stability of $\mathrm{R}$ models depends on their sizes (Figure $\mathrm{S}_{3}$ e). OR and $\mathrm{R}$ structures exhibit one type of short Mo-Mo bond length (about 2.72-2.79 $\AA$ ) with very small variation according to size (Table S2). 
Table 1 : Mo-Mo and Mo-S bond lengths (in Å) for various types of MoS $\mathrm{S}_{3}$ polymorphs.

\begin{tabular}{|c|c|c|c|c|c|c|c|c|}
\hline Bond & TO-P & Ring & WL-P & HL-P & L-P & ıT'-like & EXAFS* & EXAFS $^{* *}$ \\
\hline Mo-Mo short & 2.76 & 2.75 & 2.77 & 2.76 & 2.90 & 2.79 & 2.75 & 2.75 \\
\hline Mo-Molong & 3.08 & -- & -- & -- & -- & 3.16 & 3.16 & -- \\
\hline Mo-S $\mathrm{S}_{\text {short }}$ & 2.27 & 2.29 & 2.30 & 2.31 & 2.31 & 2.33 & -- & -- \\
\hline Mo-S & 2.46 & 2.46 & 2.45 & 2.46 & 2.46 & 2.47 & -- & -- \\
\hline Mo-S ${ }_{\text {avg }}$ & 2.42 & 2.39 & 2.39 & 2.40 & 2.40 & 2.44 & 2.44 & 2.44 \\
\hline
\end{tabular}

*according to Ref. ${ }^{36}$, ${ }^{* *}$ according to Ref. ${ }^{28}$

1D periodic structures (WL-P) containing various numbers of Mo per unit cell depending on the wave amplitude were optimized (Figure S6 and Figure $2 \mathrm{~d}$ ). Finally, a more complex structure consists of a helical periodic (HL-P) structure as shown in Figure 2 e, which results from $3 \mathrm{D}$ distortion of the $\mathrm{R}$ structures induced by the change of the relative orientation of successive $\mathrm{S}_{2}$ dimers. Interestingly, these more complex $3 \mathrm{D}$ structures are very similar to the one proposed by Hibble et al. ${ }^{37}$ Table 1 shows that these periodic structures also exhibit one short Mo-Mo bond (about 2.76-2.77 $\AA$ ) as for OR and R structure. The Mo-Mo PCF analysis (Figure S8) reveals that the structural feature of this polymorph family clearly differs from TO. The mean Mo-S bond length is $\sim 2.40 \AA$, while the S-S bond length in $\mathrm{S}_{2}$ bridging dimer is $\sim 2.05 \AA$ (whatever the size, except for the smallest constrained $\mathrm{Mo}_{6} \mathrm{~S}_{18}$ ring, Table S2).

Comparing the Mo-Mo and Mo-S bond-lengths of various explored structures with EXAFS data (Table 1), we observe that all the chain like structures (linear, WL, WL-P, HL-P and R) have only one Mo-Mo bond in contrast with TO. This type of polymorph would thus explain the fact that EXAFS data do not identify the longer Mo-Mo distance in some experimental $\mathrm{MoS}_{3}$ samples, whereas it may exist in other ones which would be of TO type. ${ }^{28}$

$\mathrm{MoS}_{3}$ patches with $1 \mathrm{IT}^{\prime}-\mathrm{MoS}_{2}$ like structure. Ab-initio molecular dynamics (AIMD) was performed to explore if new possible structures can be revealed. Starting AIMD from TO metastable conformers identified at o $\mathrm{K}$ after geometry optimization (such as the one highlighted for $\mathrm{Mo}_{6} \mathrm{~S}_{18}$ in Figure $\mathrm{S}_{2}$ ), the system explored rapidly a large configurational space. The structural evolutions of the $\mathrm{Mo}_{6} \mathrm{~S}_{18}$ and $\mathrm{Mo}_{9} \mathrm{~S}_{27}$ oligomers (Figures $\mathrm{S}_{9}$ and $\mathrm{S}_{10}$ ) show that the triangles rapidly interconnect by one $\mu_{2}-S_{2}$ species plus one $\mu_{3}-\mathrm{S}$ species as we found by static optimiza- tion. Moreover, the dynamic evolution proceeds further and reaches, after a few picoseconds, more condensed rearrangements exhibiting respectively 4 and 8 adjacent triangular clusters interconnected by $\mu_{3}$-S species. Figure $\mathrm{S}_{3}$ illustrates the final products obtained after quenching at o K both $\mathrm{Mo}_{6} \mathrm{~S}_{18}$ and $\mathrm{Mo}_{9} \mathrm{~S}_{27}$ condensed structures. For $\mathrm{Mo}_{12} \mathrm{~S}_{36}$, the corresponding optimized structure is represented in Figure $1 \mathrm{f}$. The structural patterns of these triangular $\mathrm{Mo}_{3}$ in $\mathrm{Mo}_{6} \mathrm{~S}_{18}, \mathrm{Mo}_{9} \mathrm{~S}_{27}$ and $\mathrm{Mo}_{12} \mathrm{~S}_{36}$ are very similar to the one found in the $1 T^{\prime}$ polymorph of $\mathrm{MoS}_{2}$, where $\mu_{3}$-S atom are located in hollow sites of $\mathrm{Mo}_{3}$ triangles, with an alternate position either above or below the Mo plane. Note, however, that the edge/surface ratio needs to be appropriate to keep the nominal $\mathrm{MoS}_{3}$ stoichiometry. Indeed, as discussed below, a nanoribbon with similar stability satisfies this constraint. Actually, the PCF analysis of $\mathrm{Mo}_{12} \mathrm{~S}_{36}$ reveals that two main Mo-Mo distances are observed: one short at $2.79 \AA$ and one long at $3.16 \AA$ (Table 1 and Figure $\mathrm{S}_{4}$ ). This implies that the $\mathrm{Mo}_{12} \mathrm{~S}_{36}$ condensed structure is actually closer to the ${ }^{1 T}$ ' phase of $\mathrm{MoS}_{2}$ with specific ordering of the contracted and expanded $\mathrm{Mo}_{3}$ triangles within the structure, whereas one single long Mo-Mo bond is reported for the $1 \mathrm{~T}$ phase. ${ }^{53}$ Interestingly, the $\mathrm{NbS}_{3}$ structure could also exhibit a nano-ribbon made of two infinite $\mathrm{Nb}$ rows arranged in similar way as in $\mathrm{Mo}_{6} \mathrm{~S}_{18}$ cluster. ${ }^{54,55}$ The simulation of an analogous $2 \mathrm{D}$ periodic $\mathrm{MoS}_{3}$ nano-ribbon (Figure Si1) reveals the presence of short Mo-Mo distances co-existing with significantly longer one.

This structural analysis indicates that if EXAFS reports the presence of two types of Mo-Mo bonds (short or long), it is difficult to discriminate whether they are due to the formation of one single polymorph or a mixture of polymorphs. To go beyond, we evaluate in what follows the relative stability of these various polymorphs. 
Energetics analysis. Figure 3 reports the growth energy (at o K, without ZPE corrections) as a function of the size of the various polymorphs described in the previous section. The impact of ZPE and temperature is reported in Figure S12 which shows that it is more pronounced for the larger size clusters as compared to smaller size ones. In most of the cases, entropy and thermal corrections stabilize the clusters for higher temperature. However, these thermal and entropic effects influence only moderately the main energetic trends, so we present the results considering o K energies in what follows.

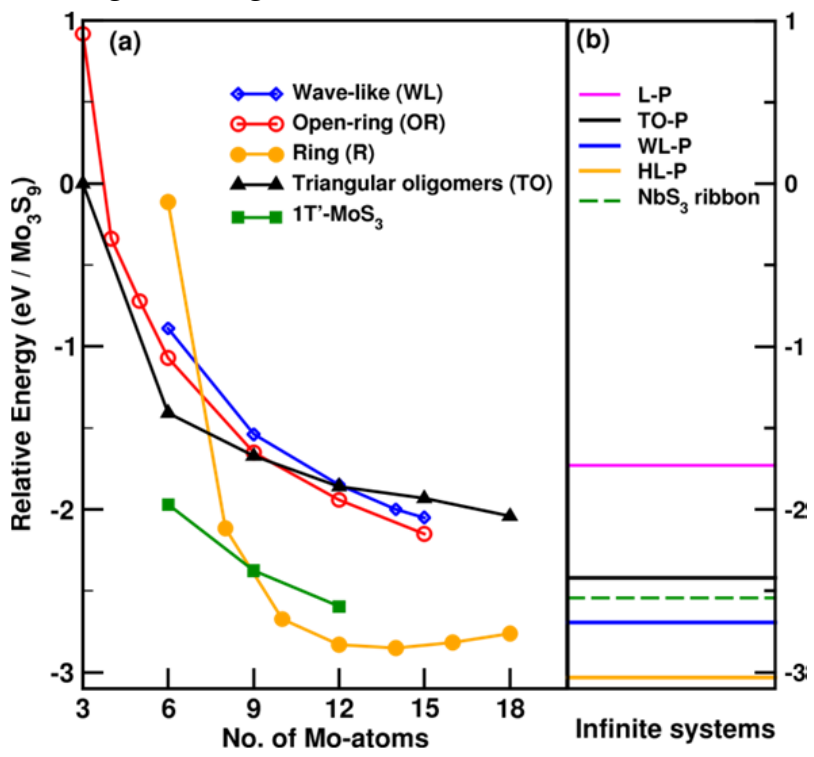

Figure 3: Growth energies of (a) 5 relevant types of $\mathrm{MoS}_{3}$ polymorphs as a function of size (reference energy is the $\mathrm{Mo}_{3} \mathrm{~S}_{9}$ triangular cluster), (b) corresponding periodic structures: L-P, TO-P, WL-P, HL-P and $\mathrm{NbS}_{3}$-like $\mathrm{MoS}_{3}$ ribbon.

On the growth energy diagram (Figure 3), as expected all curves (except the one of $\mathrm{R}$ ) exhibit a continuously decreasing trend as a function of size, with a continuously decreasing slope. However, even for large sizes considered in the present study (up to $16 \mathrm{Mo}$ ), a plateau in energy is not yet reached and the asymptotic limit value for infinite size can only be estimated of the polymorphs placed in periodic supercells as described before for L-P, TO-P, WL$P$ and HL-P.

The OR and WL polymorphs share a similar internal structure. Hence, they are nearly iso-energetic and their relative energy remains constant as a function of the size. Nevertheless, WL is slightly less favored compared to OR due to the point defects induced by the change in the tilting angle of the $\mathrm{S}_{2}$ dimer (as described before).

The relative energies between other families of $\mathrm{MoS}_{3}$ polymorphs of different types are, however, size dependent. Considering first the oD TO and OR structures, the energy values of the smallest $\mathrm{Mo}_{3} \mathrm{~S}_{9}$ and $\mathrm{Mo}_{6} \mathrm{~S}_{12}$ clusters reveal that $\mathrm{TO}$ is strongly stabilized with respect to $\mathrm{OR}$ by $\sim 1 \mathrm{eV}$ for $\mathrm{Mo}_{3} \mathrm{~S}_{9}$. By contrast, the infinite TO-P polymorph is less stable than WL-P and HL-P. The inversion of stability between TO and OR or WL occurs for 9-12 Mo atoms. For larger oligomers, OR or WL are more stable.

If we consider the lowest energy L-P model (pink in Figure 3), it is obvious that it is significantly less stable than all other polymorphs and cannot be considered relevant for the a-MoS 3 phase. Our more stable models preferentially exhibit curved or bent chains such as found in $\mathrm{OR} / \mathrm{WL} / \mathrm{HL}$. This is in qualitative agreement with Hibble's bent chain models exhibiting numerous elbows. ${ }^{37}$

The most striking energetic result concerns the $\mathrm{R}$ model. Indeed, for size greater than 8 Mo the R models emerge as the thermodynamically most stable arrangement except for the HL-P polymorph which is competitive with the lowest energy R structure reached at 14 Mo. The R models are strongly stabilized with respect to OR due to the absence of edge energies after ring closure. This edge effect is generally stronger for OR/WL than for TO which explains also the higher energies of OR/WL for small sizes. In agreement with these considerations, the stabilization of the periodic TO-P system with respect to the larger TO is less pronounced than for WL. The periodicity in WL-P also enables to wipe this edge effect out. So the stability of WL-P may compete with $\mathrm{R}$, when the ring-strain is nonnegligible.

As we have explained in the previous section, OR may grow in a helical structure HL/HL-P, which has the lowest energy we could identify for $\mathrm{MoS}_{3}$ models. This stabilization is induced by the close proximity of two helical rings which supplements Van-der-Waals interactions, not present in any other periodic system.

Finally, Figure 3 demonstrates that the stability of the 1T'like $\mathrm{MoS}_{3}$ polymorph, including the $\mathrm{NbS}_{3}$-like nanoribbon, strongly competes with many other phases. This result is also consistent with the AIMD simulation which highlighted the fast transformation from TO into $1 \mathrm{~T}$ '-like $\mathrm{MoS}_{3}$ clusters. For sizes up to $12 \mathrm{Mo}$ atoms, $1 \mathrm{~T}^{\prime}$-like $\mathrm{MoS}_{3}$ clusters are more stable than OR/WL and TO. For the $1 \mathrm{D}$ structures, the $\mathrm{MoS}_{3}$ nano-ribbon is slightly more stable than TO-P but less stable than WL-P. Hence, here again this would mean that size effect will modulate the relative stability of this polymorph which would be favored at small sizes.

\section{Spectroscopic analysis}

IR spectrum of TO and 1T'-MoS $\mathrm{M}_{3}$ polymorphs: As a preliminary important analysis detailed in Supplementary Information SI.4, the empirical IR assignment of $\mathrm{MoS}_{3}$ based on $\left(\mathrm{NH}_{4}^{+}\right)_{2}\left[\mathrm{Mo}_{3} \mathrm{~S}_{13}\right]^{2-}$ reference compound ${ }^{27}$ must be questioned due to the effects of the $2 \mathrm{e}^{-}$charge and S/Mo over-stoichiometry involved in this reference compound. Weber et al. ${ }^{27}$ have assigned the two characteristic peaks at $520-525 \mathrm{~cm}^{-1}$ to $\mu_{1}-S_{2}$ and $545-555 \mathrm{~cm}^{-1}$ to $\mu_{2}-S_{2}$. While the simulation confirms that in $\left[\mathrm{Mo}_{3} \mathrm{~S}_{13}\right]^{2-}$ the two characteristic peaks at $520-525 \mathrm{~cm}^{-1}$ and $545-555 \mathrm{~cm}^{-1}$ can be 
assigned to $\mu_{1}-S_{2}$ and to $\mu_{2}-S_{2}$ respectively, the S-S vibrational frequencies of these two species cannot be easily distinguished anymore in the neutral $\left[\mathrm{Mo}_{3} \mathrm{~S}_{9}\right]^{\circ}$ due to the significant shift of the S-S frequency in $\mu_{1}-S_{2}$ with or without charge. Moreover, $\mu_{1}-\mathrm{S}$ or $\mu_{2}-\mathrm{S}$ species exist in $\left[\mathrm{Mo}_{3} \mathrm{~S}_{9}\right]^{\circ}$ as well as in the larger TO previously identified, while they are not present in $\left[\mathrm{Mo}_{3} \mathrm{~S}_{13}\right]^{2-}$.

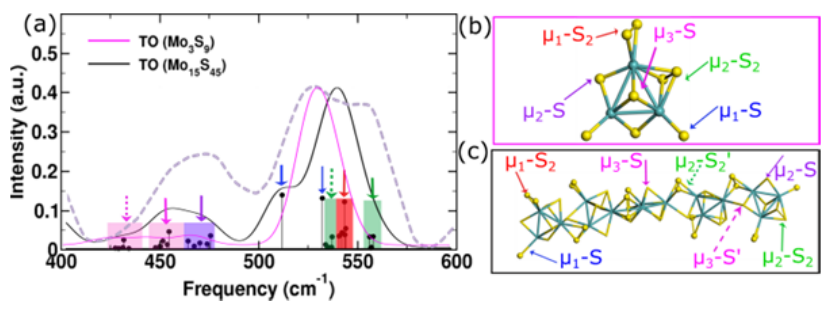

Figure 4 : (a) IR spectra of $\mathrm{Mo}_{3} \mathrm{~S}_{9}$ (pink line), $\mathrm{TO} \mathrm{Mo}_{15} \mathrm{~S}_{45}$ (black line) and $1 \mathrm{~T}^{\prime}$ - $\mathrm{MoS}_{3}$ cluster (blue line). Coloured arrows point the contributions of the various $\mathrm{S}$ species as defined in the structural models of (b) triangular $\mathrm{Mo}_{3} \mathrm{~S}_{9}$ and (c) TO $\mathrm{Mo}_{15} \mathrm{~S}_{45}$. All simulated spectra have been renormalized while keeping the highest intensity peak fixed. Experimental IR spectrum (dashed line) from ref. ${ }^{27}$

The simulation of IR spectra performed (e.g. Figure 4 a), are compared with the $a-\mathrm{MoS}_{3}$ bulk IR spectrum provided in Ref. ${ }^{27}$, similar to other published spectra., ${ }^{3,20}$ Since the region below $400 \mathrm{~cm}^{-1}$ involves mixed vibrational modes of Mo-S and Mo-Mo, we focus in the following on the region $400-600 \mathrm{~cm}^{-1}$. As we expect from the preliminary analysis of $\mathrm{Mo}_{3} \mathrm{~S}_{9}$, all modes involving $\mathrm{S}_{2}$ dimers such as $\mu_{2}-S_{2}$ or $\mu_{1}-S_{2}$ appear between $535-558 \mathrm{~cm}^{-1}$ (Table $S_{4}$ ). For TOs larger than $\mathrm{Mo}_{3} \mathrm{~S}_{9}$ (including $\mathrm{Mo}_{15} \mathrm{~S}_{45}$ in Figure 4), two types of $\mu_{2}-S_{2}$ exist: one located on each triangular cluster $\left(545-558 \mathrm{~cm}^{-1}\right)$ and the one at the interconnection of two triangles $\left(535-539 \mathrm{~cm}^{-1}\right)$. Furthermore, $\mu_{1}-S_{2}$ appears in between two types of $\mu_{2}-S_{2}\left(538-546 \mathrm{~cm}^{-1}\right)$ and exhibits the highest intensity of the $S_{2}$ species. Since the frequencies of $\mu_{2}-S_{2}$ and $\mu_{1}-S_{2}$ are very close, they produce a single broad peak in this spectrum region. Thus, considering only these two S species, it is impossible to explain the origin of the two high intensity peaks revealed in the 500-575 $\mathrm{cm}^{-1}$ region of the experimental IR spectrum. However, the two $\mu_{1}-S_{1}$ species of the triangular $\mathrm{Mo}_{3} \mathrm{~S}_{9}$, give rise to two high intensity peaks at $512 \mathrm{~cm}^{-1}$ and $532 \mathrm{~cm}^{-1}$ which may thus contribute to the region observed in the experimental data at about $525 \mathrm{~cm}^{-1}$. This interpretation has never been proposed in the experimental literature due to the use of the $\left(\mathrm{NH}_{4}{ }^{+}\right)_{2}\left[\mathrm{Mo}_{3} \mathrm{~S}_{13}{ }^{2-}\right]$ reference, which does not contain $\mu_{1}-S_{1}$ species. Figure $S_{13}$ illustrated the effect of TO size on the evolution of the IR spectra: the intensity of the first $\mu_{1}-S_{1}$ high intensity peak decreases with increasing size because $\mu_{1}-S_{1}$ are located at TO edges.

Finally, in the broad region between 425 and $475 \mathrm{~cm}^{-1}$, the simulation reveals a contribution of three types of species:

- $\mu_{3}-\mathrm{S}$ on each triangular cluster at $\sim 430 \mathrm{~cm}^{-1}$,
- $\mu_{3}-\mathrm{S}$ at the interconnection of the triangular clusters at $\sim 425 \mathrm{~cm}^{-1}$,

- $\mu_{2}-\mathrm{S}$ species on each triangular cluster at $446-475 \mathrm{~cm}^{-1}$. Increasing the size of TO up to the infinite TO-P enhances the intensity of this broad low wave number region with respect to the $500-575 \mathrm{~cm}^{-1}$ region (Figure S13).

However, considering one single type of TO polymorph makes it difficult to recover the experimental IR spectrum. As the previous energetic analysis showed that TO polymorphs are less stable for large size than chain like ones (OR, R, WL) or $1 \mathrm{~T}^{\prime}-\mathrm{MoS}_{3}$ clusters, we investigate their spectroscopic features next.

IR spectrum of chain like (OR, $R$ and WL) polymorphs. The simulated spectra of chain like models OR and $\mathrm{R}$ reveal that they exhibit all very similar features (Figures $\mathrm{S}_{14}$ and $\mathrm{S}_{15}$ ): as an example, $\mathrm{R} \mathrm{Mo}_{14} \mathrm{~S}_{42}$ is also reported in Figure 5. It is important to recall that no $\mu_{1}-S_{2}$ species are present and that $\mu_{2}-S_{2}$ and $\mu_{2}-S$ are predominantly located in the internal chain (Figure 1). Thus, the simulated spectra are dominated by one intense region between 531 to $547 \mathrm{~cm}^{-1}$ due to $\mu_{2}-S_{2}$ species (Table $S_{5}$ ). Increasing the size of $\mathrm{OR}$ and $\mathrm{R}$ induces a slight shift to higher frequencies of the $\mu_{2}-S_{2}$ region. This trend is correlated to the slight increase of the S-S bond length (from 2.053 $\AA$ to $2.067 \AA$ ) when the size increases. OR also contains $4 \mu_{1}-S$ at edges with a peak at $\sim 508 \mathrm{~cm}^{-1}$, which intensity decreases with increasing size due to the loss of edge effects. Finally, the $\mu_{2}-S$ modes contribute to the broad region $450-475 \mathrm{~cm}^{-1}$, depending on sizes (Table $\mathrm{S}_{5}$ ). Due to the absence of the $\mu_{3}-S$ contributions and the IR intensity quenching interaction between $\mu_{2}-S$ species, this low frequency region is much less intense for the chainlike models than in TO polymorphs.

WL exhibits a similar trend as TO for the regions due to $\mu_{2}-S_{2}$ and $\mu_{2}-S$ contributions (Figure S16). In addition, the $4 \mu_{1}-S$ at edges imply the appearance of a marked shoulder around $515 \mathrm{~cm}^{-1}$ for the small sizes. As for OR, this edge effect vanishes for very large and infinite size, such as in WL-P. Here again, the broad region $450-475 \mathrm{~cm}^{-1}$ exhibits a very weak intensity. To enhance this region, one should break the high symmetry of the R, WL and OR systems by generating a helical system as shown for HL-P in Figure 5. In this case, the $3 \mathrm{D}$-distortion of the chain enhances the contributions $\mu_{2}-S$ which are not located all perfectly located in the plane of the circular region of HL. 


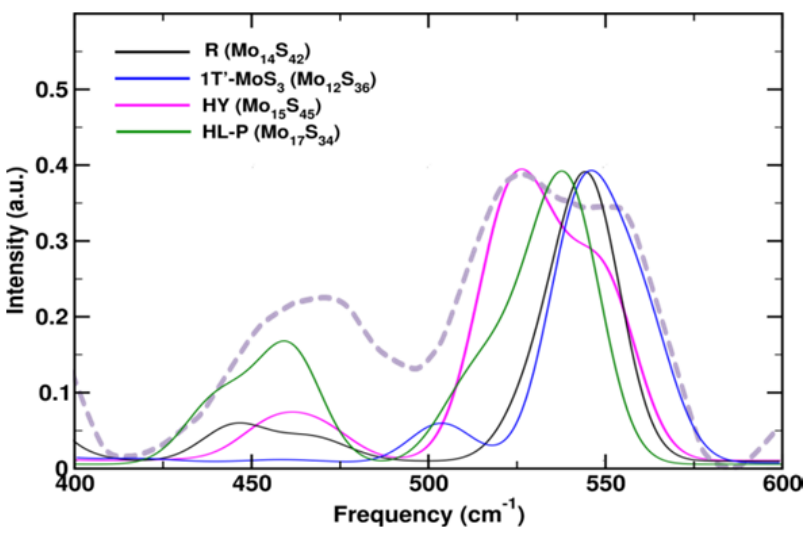

Figure 5 : IR spectrum of R, HL-P, HY, and $1 T^{\prime}-\mathrm{MoS}_{3}$ polymorphs (solid lines). All simulated spectra have been renormalized while keeping the highest intensity peak fixed. Dashed curve : experimental IR spectrum from ref. ${ }^{27}$

Finally, Figure 5 reports the simulated IR spectrum for the $1 \mathrm{~T}^{\prime}-\mathrm{MoS}_{3}$ cluster $\left(\mathrm{Mo}_{12} \mathrm{~S}_{36}\right)$ revealing that the predominant $\mu_{2}-S_{2}$ species and the $2 \mu_{1}-S_{2}$ present at edges exhibit a slightly broad region at about $550 \mathrm{~cm}^{-1}$, which matches well the high frequency region of the experimental spectrum.

\section{DISCUSSION}

Our revisited assignment of the IR spectrum of $\mathrm{MoS}_{3}$ reveals that the higher region at $545-555 \mathrm{~cm}^{-1}$ is assigned to both $\mu_{1}-S_{2}$ and $\mu_{2}-S_{2}$ when they exist as in TO polymorphs (with at least $6 \mathrm{Mo}$ ), or to $\mu_{2}-S_{2}$ only as in chain like models (R, OR, WL, HL), or to edges of $1 \mathrm{~T}^{\prime}-\mathrm{MoS}_{3}$. The IR region at $520-525 \mathrm{~cm}^{-1}$ is reproduced only if $\mu_{1}-\mathrm{S}$ species are present either at edges of the chain like and TO models or on the triangular $\mathrm{Mo}_{3} \mathrm{~S}_{9}$.

Moreover, the energetic analysis showed that TO models are thermodynamically stable only for the smallest size as $\mathrm{Mo}_{3} \mathrm{~S}_{9}$, whereas for larger sizes, the chain like (OR, R, WL, $\mathrm{HL}$ ) or the $1 \mathrm{~T}^{\prime}-\mathrm{MoS}_{3}$ cluster become more stable. Hence, the $\mathrm{MoS}_{3}$ phase is actually constituted of various polymorphs as a function of the size of the oligomers. This is reflected in the IR spectrum resulting from the contribution of these various polymorphs. At this stage, we can propose the two following possible combinations of polymorphs:

- Triangular $\mathrm{Mo}_{3} \mathrm{~S}_{9}$ (contributing to the region 520-525 $\mathrm{cm}^{-1}$ ) and ${ }_{1} \mathrm{~T}^{\prime}-\mathrm{MoS}_{3}$ cluster such as $\mathrm{Mo}_{12} \mathrm{~S}_{36}$ or even $\mathrm{NbS}_{3}$-ribbon for larger size (contributing to the region $545-555 \mathrm{~cm}^{-1}$ )

- Triangular $\mathrm{Mo}_{3} \mathrm{~S}_{9}$ (contributing to the region 520-525 $\mathrm{cm}^{-1}$ ) and larger chain like models such as OR, R, WL or HL (contributing to the region $545-555 \mathrm{~cm}^{-1}$ and to the region $520-525 \mathrm{~cm}^{-1}$ when $\mu_{1}-\mathrm{S}$ species are present at edges).
To further investigate the combination of Triangular $\mathrm{Mo}_{3} \mathrm{~S}_{9}$ with chain like models, we simulated a Hybrid (HY) structure combining both one OR structure with two triangular $\mathrm{Mo}_{3} \mathrm{~S}_{9}$ clusters located at its edges (Figure $\mathrm{S}_{3} \mathrm{~d}$ ). As expected, this mixed structure recovers the two high frequency regions (Figure 5) of the experimental spectrum. The $\mu_{1}-\mathrm{S}$ species of the triangular $\mathrm{Mo}_{3} \mathrm{~S}_{9}$ give rise to a broad region at $520 \mathrm{~cm}^{-1}$ (Figure $\mathrm{S}_{17}$ ). In addition, one $\mu_{1}-S_{2}$ of the triangular $\mathrm{Mo}_{3} \mathrm{~S}_{9}$ and $\mu_{2}-\mathrm{S}_{2}$ of the triangles and of the OR chain gives rise to the upper part of the experimental spectrum $\left(533-552 \mathrm{~cm}^{-1}\right)$. With increasing size this upper region gains relative intensity due to more numerous $\mu_{2}-S_{2}$ contributions with respect to $\mu_{1}-S$. Similarly, the lowest broad region between 450 and $500 \mathrm{~cm}^{-1}$ is also increasingly visible due to the increased number of $\mu_{2}-S$ within the chain (Figure $S_{14}$ ). To enhance the intensity of this region $450-500 \mathrm{~cm}^{-1}, 3 \mathrm{D}$-chain distortion as in HL is required.

XPS experiments of $\mathrm{MoS}_{3}$ usually reveal two species $\mu_{2}-\mathrm{S}_{2}$ and $\mu_{1}-S_{2}$ in the $S$ 2p region with respective binding energies of 162.9 and 161.6. In other words, the corresponding relative binding energy, $\Delta B E=B E\left(\mu_{2}-S_{2}\right)-B E\left(\mu_{1}-S_{2}\right)$, is +1.3 $\mathrm{eV}^{27}$ The DFT calculation of the core level shift between $\mu_{2}-S_{2}$ and $\mu_{1}-S_{2}$ species yield a $\triangle B E$ of $1.55 \mathrm{eV}$ in $1 T^{\prime}-\mathrm{MoS}_{3}$ and $1.57 \mathrm{eV}$ in TO $\mathrm{Mo}_{18} \mathrm{~S}_{54}$ (Table $\mathrm{S}_{3}$ ). Given the DFT accuracy, this value is in reasonable agreement with experiment.

However, in chain like models, $\mu_{2}-S_{1}$ are present instead of $\mu_{1}-S_{2}$ which may raise question about the coherence with XPS. Our DFT calculations show that $\triangle B E=B E\left(\mu_{2}-S_{2}\right)-$ $\mathrm{BE}\left(\mu_{2}-\mathrm{S}\right)$ fluctuates between 1.14 and $1.65 \mathrm{eV}$ for various WL and OR models. So, these models remain also compatible with the S 2p XPS spectrum, i.e., XPS does not allow to discriminate between these different models.

Regarding the $\mu_{1}-\mathrm{S}$ species present at edges of TO, WL and $\mathrm{OR}$, the question of the compatibility with XPS must be also addressed. Here, $\Delta B E=B E\left(\mu_{2}-S_{2}\right)-B E\left(\mu_{1}-S\right)$ is shifted to significantly higher energy: $+2.84 \mathrm{eV}$ in $\mathrm{TO} \mathrm{Mo}_{15} \mathrm{~S}_{45}$, $+2.31 \mathrm{eV}$ in $\mathrm{WL}(\mathrm{Mo}=14)$ and $+2.23 \mathrm{eV}$ in $\mathrm{OR}(\mathrm{Mo}=15)$ also meaning that the binding energy of $\mu_{1}-S_{2}$ is significantly greater than the one of $\mu_{1}-S$. However, these $\mu_{1}-S$ species are not identified in the $S$ 2p XPS spectrum. As a consequence, if these $\mu_{1}-S$ exist, they must be present in very low concentration, i.e., significantly smaller than the other $S$ species. This low concentration of $\mu_{1}-S$ does not contradict the IR spectrum since we noticed that in our proposed models, their number is comprised between 2 and 4 per polymorph. For the model $\mathrm{Mo}_{15} \mathrm{~S}_{45}$, this represents less than $10 \%$ of $\mathrm{S}$ species. Since the bulk $\mathrm{MoS}_{3}$ phase is constituted by a distribution of polymorphs of various sizes going beyond $\mathrm{Mo}_{15} \mathrm{~S}_{45}$, this percentage is certainly much lower. Due to the higher sensitivity of IR to these $\mu_{1}-\mathrm{S}$ species, their low concentration does not prevent them to be visible in IR spectra, while they are not seen by XPS. 


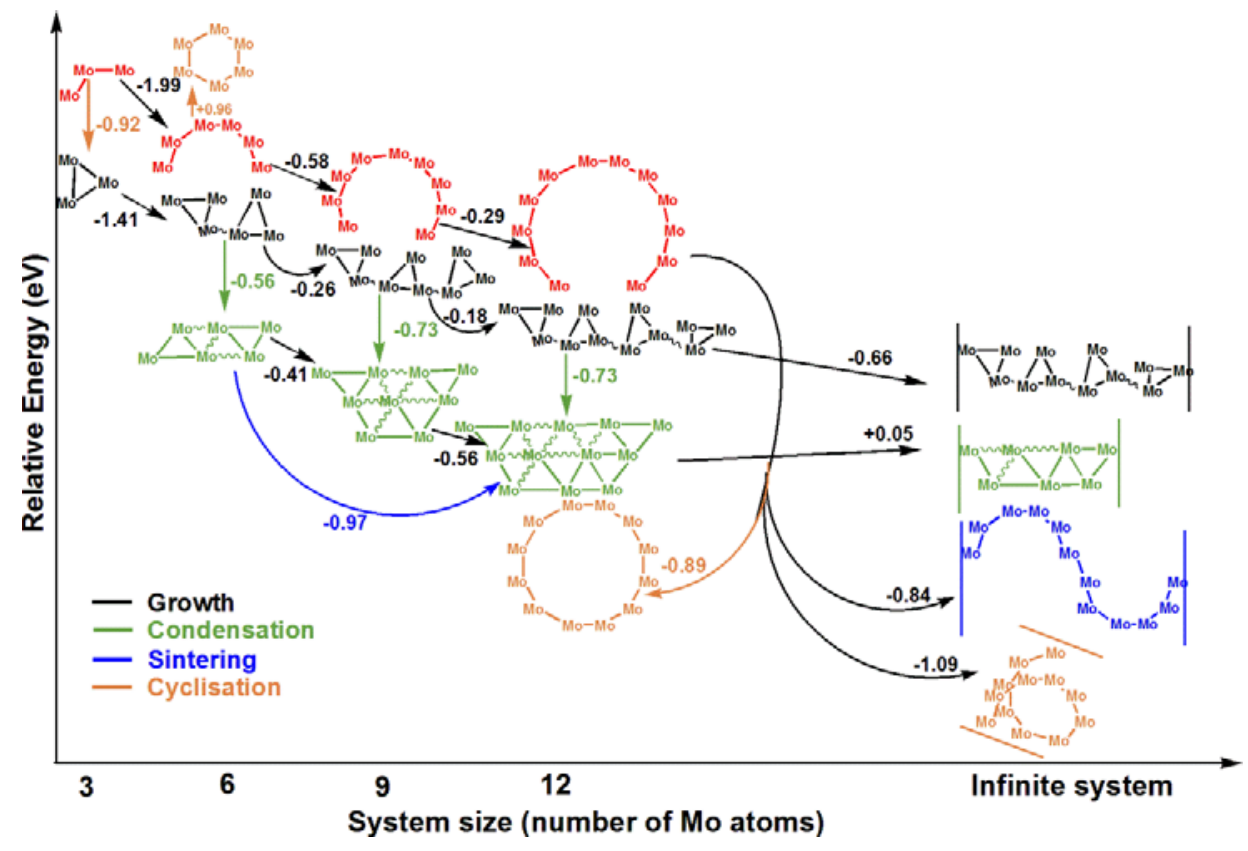

Figure 6: Possible transformation pathways of the $\mathrm{MoS}_{3}$ polymorphs and correspondingly free energy change.

In both aforementioned combinations of $\mathrm{MoS}_{3}$ polymorphs, the Mo-Mo bond length should exhibit the short ( 2.72-2.75 $\AA$ ) and long (2.96-3.16 $\AA$ ) contribution as reported by some EXAFS analysis. ${ }^{36}$ Depending on the proportion of triangular $\mathrm{Mo}_{3} \mathrm{~S}_{9}$, we may suspect that the long Mo-Mo bond vanishes and the short one only becomes predominant. This could explain that other EXAFS analysis reported this short Mo-Mo bond only. ${ }^{2,28,33,36}$ These different observations may also originate from the genesis (synthesis pathway) of the $\mathrm{MoS}_{3}$ phase which may result in atomically different a-MoS 3 phases depending on the experimental conditions.

As illustrated by the thermodynamic energy plot (Figure 3), the triangular $\mathrm{Mo}_{3} \mathrm{~S}_{9}$ is the most stable one for the smallest size. If the nucleation of $\mathrm{MoS}_{3}$ starts from such triangular clusters, it is highly improbable that it transforms into chain like OR $\mathrm{Mo}_{3} \mathrm{~S}_{9}$ because of the high reaction endergonicity $(\Delta \mathrm{G} \sim 1 \mathrm{eV}$ at $\mathrm{T}=298.15 \mathrm{~K}$, Figure $\mathrm{S} 12)$. Concomitantly, if the nucleation generates $\mathrm{OR} \mathrm{Mo}_{3} \mathrm{~S}_{9}$, the reverse reaction to $\mathrm{TO}$ is exergonic. For larger TO, the transformation into chain like oligomers (OR, R, WL, HL) would be thermodynamically favored (Figure S12). Although further investigations are needed, it is strongly suspected that kinetic limitations of breaking several Mo$\mathrm{S}$ and Mo-Mo bonds to open the interconnected triangular $\mathrm{Mo}_{3} \mathrm{~S}_{9}$ clusters will prevent the transformation from TO into the chain like polymorphs. Hence, the formation of chain like polymorphs would need to be promoted during the genesis of the $\mathrm{Mo}_{3} \mathrm{~S}_{9}$ embryos through specific reaction conditions (precursors or even support effects).

Assuming that the triangular $\mathrm{Mo}_{3} \mathrm{~S}_{9}$ clusters are first formed, they could grow by connecting one to each other to form TO oligomers of increasing sizes. Nevertheless, as we have shown by AIMD, the small TO intermediates $\mathrm{Mo}_{6} \mathrm{~S}_{18}, \mathrm{Mo}_{9} \mathrm{~S}_{27}$ and $\mathrm{Mo}_{12} \mathrm{~S}_{36}$ are prone to be further transformed into $1 \mathrm{~T}$ '- $\mathrm{MoS}_{3}$ clusters through a condensation step (Figure 6). This striking dynamic behavior reveals that metastable $\mathrm{TO}$ conformers might readily transform into a 1T'-like $\mathrm{MoS}_{3}$ polymorph.

The TO into $1 \mathrm{~T}^{\prime}-\mathrm{MoS}_{3}$ transformation is exergonic $(\Delta \mathrm{G} \sim-$ 0.56 to $-0.73 \mathrm{eV}$ for the three $\mathrm{Mo}_{6} \mathrm{~S}_{18}, \mathrm{Mo}_{9} \mathrm{~S}_{27}$ and $\mathrm{Mo}_{12} \mathrm{~S}_{36}$ clusters). As revealed by the AIMD simulation, this condensation mechanism occurs if the relative positions of the various dimeric and monomeric $\mathrm{S}$ species are optimal (supplementary information SI.2). Otherwise, it is blocked and the oligomerization of the triangular species can continue. Once the first embryos of the $1 \mathrm{~T}^{\prime}-\mathrm{MoS}_{3}$ phase are generated in the form of the structures identified by our AIMD, they could probably follow a sintering process to produce larger $\mathrm{MoS}_{3}$ ribbons inspired by the $\mathrm{NbS}_{3}$ structure. ${ }^{25,55}$ Note that the transformation of TO-P into $\mathrm{MoS}_{3}$ ribbons $\left(\mathrm{NbS}_{3}\right.$-like) is also exergonic.

In the present AIMD simulations (constant chemical composition), the obtained 1T'-like phase is thus overstoichiometric with respect to $1 \mathrm{~T}^{\prime}-\mathrm{MoS}_{2}$ and the excess $\mathrm{S}$ atoms are located at the edges of the $1 \mathrm{~T}^{\prime}$-nanostructure. 
Similarly over-stoichiometric triangular or hexagonal nanostructures have been reported for $2 \mathrm{H}-\mathrm{MoS}_{2} .{ }^{56,57}$ The removal of the excess sulfur from the edge sites in the presence of $\mathrm{H}_{2}$ as it is usual in sulfo-reductive conditions may lead to $1 \mathrm{~T}^{\prime}-\mathrm{MoS}_{2}{ }^{12}$ which can further transform into $2 \mathrm{H}_{-} \mathrm{MoS}_{2} \cdot{ }^{58-65}$ The easy formation of the $1 \mathrm{~T}^{\prime}-\mathrm{MoS}_{3}$ cluster also justifies the above proposal of coexistence of triangular $\mathrm{Mo}_{3} \mathrm{~S}_{9}$ and $1 \mathrm{~T}^{\prime}-\mathrm{MoS}_{3}$ clusters to recover the experimental IR spectrum.

However, we cannot exclude that right from the early stage the nucleation forms a chain like cluster (if stabilized by support effect or nature of precursor) which rapidly grows by adding "linearly" other Mo atoms before transforming into TO that is energetically preferred in the gas-phase for small clusters. Furthermore, if the growth of OR proceeds further, cyclisation process from OR to $R$ would be likely considering the significant free energy gain $\left(\Delta \mathrm{G} \sim-0.89 \mathrm{eV}\right.$ at $\mathrm{T}=298.15 \mathrm{~K}$, for $\left.\mathrm{Mo}_{12} \mathrm{~S}_{36}\right)$. The fact that such ring structures have not been yet reported so far, may indicate that the first scenario is common. However, we propose that the improvement of synthesis or characterization methods could allow to identify the $\mathrm{R}$ structures. Alternatively, the a reconstruction of the terminal units of the OR structures could result in the HY structures where triangular clusters and a chain are interconnected. We have shown above that the simulated IR spectrum of these HY polymorphs is also compatible with the experimental one.

\section{CONCLUSIONS}

By means of DFT calculations, the present work provided a detailed analysis of the structural, energetic and spectroscopic properties of the a-MoS 3 amorphous phase. The challenging question of the amorphous nature of this phase was addressed by identifying several structures of possible conformers such as chain-like and triangular oligomers either previously invoked in the experimental literature or newly proposed. By simulating cluster models and periodic structures, we showed how size effects impact the relative stability of these various polymorphs.

We first ruled out the strictly linear models of $\mathrm{Mo}^{5+}\left(\mathrm{S}^{2-}\right.$ )$_{2}\left(\mathrm{~S}_{2}{ }^{2-}\right)_{1 / 2}{ }^{19,23}$ and of $\mathrm{Mo}^{4+}\left(\mathrm{S}^{2-}\right)\left(\mathrm{S}_{2}{ }^{2-}\right)$ which are both significantly less stable than triangular models or curved chain. The curvature is induced by specific orientation of $\mathrm{S}_{2}$ dimers as found in open-ring (OR), ring (R), wave-like (WL) or helical (HL) structures.

For small sizes, the triangular $\mathrm{Mo}_{3} \mathrm{~S}_{9}$ is more stable than the chain like models. Nevertheless, the free energy rapidly becomes favorable to chain-like models when increasing size. In particular, for the largest oligomers studied here $\left(\mathrm{Mo}_{15} \mathrm{~S}_{45}\right)$, OR and $\mathrm{R}$ becomes more stable than TO, while the periodic structures such WL-P and HL-P confirm that chain like models are favored.

To the best of our knowledge, the stable ring structures were never observed experimentally. So, as a first perspective to favor the formation of this appealing ring structure, we suggest that experimental studies may explore alternative synthesis pathways to prevent the formation of triangular clusters and to prompt the cyclisation process.

We proposed possible transformation pathways for the $\mathrm{MoS}_{3}$ oligomers: from their nucleation to growth accompanied eventually by condensation and cyclization steps. In particular, AIMD simulation revealed the easy transformation of the $\mathrm{MoS}_{3}$ TOs into a so-called "1T'-MoS " phase with the typical structural pattern of the $1 \mathrm{~T}$ '-MoS phase. The corresponding periodic structure should be $\mathrm{MoS}_{3}$-ribbon inherited from the $\mathrm{NbS}_{3}$ phase.

Our large variety of explored structures allowed to revisit the interpretation of experimental EXAFS, IR and XPS spectra. The DFPT simulation of IR spectra highlighted the particular contribution of Mo-S mode of $\mu_{1}-S$ species in the $525 \mathrm{~cm}^{-1}$ region, while the S-S modes of $\mu_{1}-S_{2}$ and $\mu_{2}-$ $\mathrm{S}_{2}$ contribute to the $550 \mathrm{~cm}^{-1}$ region. The core level shift calculations reveal the XPS compatibility of all S species, excepting $\mu_{1}-S$ species present at the edges of the chain like model or in the triangular $\mathrm{Mo}_{3} \mathrm{~S}_{9}$ which, therefore, should at most exist in very low concentrations. To recover the IR spectrum, we proposed relevant combinations of polymorphs. These combinations of polymorphs may also explain why EXAFS data report either one or two types of Mo-Mo bond lengths depending on the relative concentrations of each polymorph. The curved chain-like model contains only one short Mo-Mo bond, whereas the TO model contains one short and one long Mo-Mo bond length.

This in-depths theoretical study provides a rational understanding of the amorphous $\mathrm{MoS}_{3}$ phase which could be useful for improving its reactivity as well as the genesis of $\mathrm{MoS}_{2}$ phases $(1 \mathrm{~T}$ or $2 \mathrm{H})$ used in many applications : hydrotreatment, hydrogen evolution reaction, storage materials...

\section{ASSOCIATED CONTENT}

Supporting Information. SI.1 Structural analysis, SI.2 Abinitio molecular dynamics, SI.3 Thermochemistry, SI.4 Spectroscopic analysis. CIF files for relevant structures. This material is available free of charge via the Internet at http://pubs.acs.org.

\section{AUTHOR INFORMATION}

\section{Corresponding Author}

*pascal.raybaud@ifpen.fr

\section{Author Contributions}

The manuscript was written through contributions of all authors. All authors have given approval to the final version of the manuscript.

\section{Funding Sources}

Any funds used to support the research of the manuscript should be placed here (per journal style). Calculations were performed using HPC resources (Jean Zay and Occigen) from GENCI-CINES (Grant Aoo20806134) and ENER 440 from IFP Energies nouvelles. This work is part of the "RatiOnAl Design for CATalysis" (ROAD4CAT) industrial chair, project IDEXLYON funded by the French National Research Agency (ANR-16-IDEX-0005) and the Commissariat-General for 
Investment (CGI) within the framework of Investissements d'Avenir program ("Investment for the future").

\section{REFERENCES}

(1) Merki, D.; Fierro, S.; Vrubel, H.; Hu, X. Amorphous molybdenum sulfide films as catalysts for electrochemical hydrogen production in water. Chemical Science 2011, 2, 1262-1267.

(2) Tang, M. L.; Grauer, D. C.; Lassalle-Kaiser, B.; Yachandra, V. K.; Amirav, L.; Long, J. R.; Yano, J.; A, P. A. Structural and Electronic Study of an Amorphous $\mathrm{MoS}_{3}$ Hydrogen-Generation Catalyst on a Quantum-Controlled Photosensitizer. Angew Chem Int Ed Engl 2011, 50, 10203-10207.

(3) Tran, P. D.; Tran, T. V.; Orio, M.; Torelli, S.; Truong, Q. D.; Nayuki, K.; Sasaki, Y.; Chiam, S. Y.; Yi, R.; Honma, I. et al. Coordination polymer structure and revisited hydrogen evolution catalytic mechanism for amorphous molybdenum sulfide. Nat. Mater. 2016, 15, 640-646.

(4) Matsuyama, T.; Hayashi, A.; Ozaki, T.; Mori, S.; Tatsumisago, M. Electrochemical properties of all-solid-state lithium batteries with amorphous $\mathrm{MoS}_{3}$ electrodes prepared by mechanical milling. J. Mater. Chem. A 2015, 3, 14142-14147.

(5) Matsuyama, T.; Deguchi, M.; Hayashi, A.; Tatsumisago, M.; Ozaki, T.; Togawa, Y.; Mori, S. Structure Analyses of Amorphous $\mathrm{MoS}_{3}$ Active Materials in All-solid-state Lithium Batteries. Electrochemistry 2015, 83, 889-893.

(6) Ye, H.; Ma, L.; Zhou, Y.; Wang, L.; Han, N.; Zhao, F.; Deng, J.; Wu, T.; Li, Y.; Lu, J. Amorphous $\mathrm{MoS}_{3}$ as the sulfur-equivalent cathode material for room-temperature Li-S and Na-S batteries. Proc. Natl. Acad. Sci. U S A 2017, 114, 13091-13096.

(7) Ye, H.; Wang, L.; Deng, S.; Zeng, X.; Nie, K.; Duchesne, P. N.; Wang, B.; Liu, S.; Zhou, J.; Zhao, F. et al. Amorphous $\mathrm{MoS}_{3}$ Infiltrated with Carbon Nanotubes as an Advanced Anode Material of Sodium-Ion Batteries with Large Gravimetric, Areal, and Volumetric Capacities. Adv. Energy Mater. 2017, 7, 1601602.

(8) Chang, U.; Lee, J. T.; Yun, J.-M.; Lee, B.; Lee, S. W.; Joh, H.I.; Eom, K.; Fuller, T. F. In Situ Self-Formed Nanosheet $\mathrm{MoS}_{3} /$ Reduced Graphene Oxide Material Showing Superior Performance as a Lithium-Ion Battery Cathode. ACS nano 2019, 13, 1490-1498.

(9) Mei, J.; Wang, C.; Kong, L.; Liu, X.; Hu, Q.; Zhao, H.; Yang, S. Outstanding Performance of Recyclable Amorphous $\mathrm{MoS}_{3}$ Supported on $\mathrm{TiO}_{2}$ for Capturing High Concentrations of Gaseous Elemental Mercury: Mechanism, Kinetics, and Application. Environ. Sci. Technol. 2019, 53, 4480-4489.

(10) Fu, W.; Yang, S.; Yang, H.; Guo, B.; Huang, Z. 2D amorphous $\mathrm{MoS}_{3}$ nanosheets with porous network structures for scavenging toxic metal ions from synthetic acid mine drainage. J. Mater. Chem. A 2019, 7, 18799-18806.

(11) Payen, E.; Kasztelan, S.; Houssenbay, S.; Szymanski, R.; Grimblot, J. Genesis and characterization by laser Raman spectroscopy and high-resolution electron microscopy of supported molybdenum disulfide crystallites. J. Phys. Chem. 1989, 93, 65016506.

(12) Toulhoat, H.; Raybaud, P. Catalysis by transition metal sulphides: From molecular theory to industrial application; IFP énergies nouvelles publications; Editions Technip: Paris, France, 2013.

(13) Afanasiev, P.; Jobic, H.; Lorentz, C.; Leverd, P.; Mastubayashi, N.; Piccolo, L.; Vrinat, M. Low-Temperature Hydrogen Interaction with Amorphous Molybdenum Sulfides $\operatorname{MoS}_{\mathrm{x}}$.J. Phys. Chem. C 2009, 113, 4139-4146.

(14) Deng, Y.; Ting, L. R. L.; Neo, P. H. L.; Zhang, Y.-J.; Peterson, A. A.; Yeo, B. S. Operando Raman Spectroscopy of Amorphous Molybdenum Sulfide $\left(\mathrm{MoS}_{\mathrm{x}}\right)$ during the Electrochemical
Hydrogen Evolution Reaction: Identification of Sulfur Atoms as Catalytically Active Sites for $\mathrm{H}^{+}$Reduction. ACS Catal. 2016, 6, 7790-7798.

(15) Ting, L. R. L.; Deng, Y.; Ma, L.; Zhang, Y.-J.; Peterson, A. A.; Yeo, B. S. Catalytic Activities of Sulfur Atoms in Amorphous Molybdenum Sulfide for the Electrochemical Hydrogen Evolution Reaction. ACS Catal. 2016, 6, 861-867.

(16) Escalera-López, D.; Lou, Z.; Rees, N. V. Benchmarking the Activity, Stability, and Inherent Electrochemistry of Amorphous Molybdenum Sulfide for Hydrogen Production. Adv. Energy Mater. 2019, 9, 1802614.

(17) Weber, T.; Muijsers, J. C.; van Wolput, J. H. M. C.; Verhagen, C. P. J.; Niemantsverdriet, J. W. Basic Reaction Steps in the Sulfidation of Crystalline $\mathrm{MoO}_{3}$ to $\mathrm{MoS}_{2}$, As Studied by X-ray Photoelectron and Infrared Emission Spectroscopy. J. Phys. Chem. 1996, 100, 14144-14150.

(18) Diemann, E. Radiale Verteilungsfunktionen. V. Strukturuntersuchungen an nichtkristallinem Molybdäntrisulfid, Wolframtrisulfid und Molybdäntriselenid. Zeitschrift für anorganische und allgemeine Chemie 1977, 432, 127-135.

(19) Liang, K. S.; Cramer, S. P.; Johnston, D. C.; Chang, C. H.; Jacobson, A. J.; deNeufville, J. P.; Chianelli, R. R. Amorphous $\mathrm{MoS}_{3}$ and $\mathrm{WS}_{3}$. J. Non-Cryst. Solids 1980, 42, 345-356.

(20) Chang, C. H.; Chan, S. S. Infrared and Raman studies of amorphous $\mathrm{MoS}_{3}$ and poorly crystalline $\mathrm{MoS}_{2}$. Journal of Catalysis 1981, 72, 139-148.

(21) Huntley, D. R.; Parham, T. G.; Merrill, R. P.; Sienko, M. J. An EXAFS study of the thermal decomposition of molybdenum trisulfide. Inorg. Chem. 1983, 22, 4144-4146.

(22) Johnston, D. C.; Jacobson, A. J.; Silbernagel, B. G.; Frysinger, S. P.; Rich, S. M.; Gebhard, L. A. Magnetic susceptibility and electron spin resonance as probes of different magnetic species in $\mathrm{MoS}_{3}$. Journal of Catalysis 1984, 89, 244-249.

(23) Chien, F. Z.; Moss, S. C.; Liang, K. S.; Chianelli, R. R. Local and intermediate-range structure of amorphous $\mathrm{MoS}_{3}$ : Model calculation study. Phys. Rev. B 1984, 29, 4606-4615.

(24) Bhattacharya, R. N.; Lee, C. Y.; Pollak, F. H.; Schleich, D. M. Optical study of amorphous $\mathrm{MoS}_{3}$ : Determination of the fundamental energy gap. J. Non-Cryst. Solids 1987, 91, 235-242.

(25) Sourisseau, C.; Gorochov, O.; Schleich, D.M. Comparative IR and Raman studies of various amorphous $\mathrm{MoS}_{3}$ and $\mathrm{Li}_{x} \mathrm{MoS}_{3}$ phases. Mater. Sci. Eng. 1989, 3, 113-117.

(26) G.F. Khudorozhko, I.P. Asanov, L.N. Maealov, E.A. Kravtsova. The study of electronic structure of molybdenum and tungsten trisulfides and their lithium intercalates by $\mathrm{x}$-ray electron and x-ray emission and absorption spectroscopy. J. Electron Spectrosc. 1994, 68, 199-209.

(27) Weber, T.; Muijsers, J. C.; Niemantsverdriet, J. W. Structure of Amorphous MoS . J. Phys. Chem. 1995, 99, 9194-9200.

(28) Hibble, S. J.; Rice, D. A.; Pickup, D. M.; Beer, M. P. Mo Kedge EXAFS and $\mathrm{S}$ K-edge absorption studies of the amorphous molybdenum sulfides $\mathrm{MoS}_{4 \cdot 7}, \mathrm{MoS}_{3}$, and $\mathrm{MoS}_{3} \cdot \mathrm{nH}_{2} \mathrm{O}(\mathrm{n} \sim 2$ ). Inorg. Chem. 1995, 34, 5109-5113.

(29) Hibble, S. J.; Walton, R. I.; Pickup, D. M.; Hannon, A. C. Amorphous $\mathrm{MoS}_{3}$ : Clusters or chains? The structural evidence. J. Non-Cryst. Solids 1998, 232-234, 434-439.

(30) Hibble, S. J.; Feaviour, M. R.; Almond, M. J. Chemical excision from amorphous $\mathrm{MoS}_{3}$; a quantitative EXAFS study. $J$. Chem. Soc., Dalton Trans. 2001, 935-940.

(31) Hédoire, C.-E.; Cadot, E.; Villain, F.; Davidson, A.; Louis, C.; Breysse, M. Preparation and characterization of molybdenum sulfide supported on $\beta$-zeolites obtained from $\left[\mathrm{Mo}_{3} \mathrm{~S}_{4}\left(\mathrm{H}_{2} \mathrm{O}\right)_{9}\right]^{4+}$ precursor. Appl. Catal. A 2006, 306, 165-174.

(32) Wang, J.; Ng, S. H.; Chew, S. Y.; Wexler, D.; Wang, G. X.; Liu, H. K. Characterization of Nanosize Molybdenum Trisulfide for Lithium Batteries and $\mathrm{MoS}_{3}$ Structure Confirmation via Electrochemistry. Electrochem. Solid State Lett. 2007, 10, A204-A207. 
(33) Lassalle-Kaiser, B.; Merki, D.; Vrubel, H.; Gul, S.; Yachandra, V. K.; Hu, X.; Yano, J. Evidence from in situ X-ray absorption spectroscopy for the involvement of terminal disulfide in the reduction of protons by an amorphous molybdenum sulfide electrocatalyst. J. Am. Chem. Soc. 2015, 137, 314-321.

(34) Müller, A.; Diemann, E.; Krickemeyer, E.; Walberg, H. J.; Bögge, H.; Armatage, A. $\left[\mathrm{Mo}_{3}(\mathrm{IV}) \mathrm{S}\left(\mathrm{S}_{2}\right)_{6}\right]^{2-}$ from amorphous $\mathrm{MoS}_{3}$ by the reaction with $\mathrm{OH}^{-}$and $\mathrm{R}=0.015$ strucutre of $\left(\mathrm{NH}_{4}\right)_{2}\left[\mathrm{Mo}_{3}(\mathrm{IV}) \mathrm{S}\left(\mathrm{S}_{2}\right)_{6}\right]$. Eur. J. Solid State Inorg. Chem. 1993, 30, 565-572.

(35) Jiao, H.; Li, Y.-W.; Delmon, B.; Halet, J.-F. The Structure and Possible Catalytic Sites of $\mathrm{Mo}_{3} \mathrm{~S}_{9}$ as a Model of Amorphous Molybdenum Trisulfide: A Computational Study. J. Am. Chem. Soc. 2001, 123, 7334-7339.

(36) Cramer, S. P.; Liang, K. S.; Jacobson, A. J.; Chang, C. H.; Chianelli, R. R. EXAFS studies of amorphous molybdenum and tungsten trisulfides and triselenides. Inorg. Chem. 1984, 23, 12151221.

(37) Hibble, S. J.; Wood, G. B. Modeling the structure of amorphous $\mathrm{MoS}_{3}$ : a neutron diffraction and reverse Monte Carlo study. J. Am. Chem. Soc. 2004, 126, 959-965.

(38) Khudorozhko, G. F.; Asanov, I. P.; Mazalov, L. N.; Kravtsova, É. A.; Parygina, G. K.; Fedorov, V. E.; Mironov, Y. V. X-ray photoelectron, emission, and absorption studies of the electronic structure of molybdenum and tungsten trisulfides and their intercalates. J. Struct. Chem. 1994, 35, 823-833.

(39) Li, Y.; Yu, Y.; Huang, Y.; Nielsen, R. A.; Goddard, W. A.; Li, Y.; Cao, L. Engineering the Composition and Crystallinity of Molybdenum Sulfide for High-Performance Electrocatalytic Hydrogen Evolution. ACS Catal. 2015, 5, 448-455.

(40) Baloglou, A.; Ončák, M.; Grutza, M.-L.; van der Linde, C.; Kurz, P.; Beyer, M. K. Structural Properties of Gas Phase Molybdenum Sulfide Clusters $\left[\mathrm{Mo}_{3} \mathrm{~S}_{13}\right]^{2-},\left[\mathrm{HMo}_{3} \mathrm{~S}_{13}\right]^{-}$, and $\left[\mathrm{H}_{3} \mathrm{Mo}_{3} \mathrm{~S}_{13}\right]^{+}$as Model Systems of a Promising Hydrogen Evolution Catalyst. J. Phys. Chem. C 2019, 123, 8177-8186.

(41) Kresse, G.; Hafner, J. Ab initio molecular dynamics for liquid metals. Phys. Rev. B 1993, 47, 558-561.

(42) Kresse, G.; Furthmüller, J. Efficient iterative schemes for $\mathrm{ab}$ initio total-energy calculations using a plane-wave basis set. Phys. Rev. B 1996, 54, 11169-11186.

(43) Kresse, G.; Furthmüller, J. Efficiency of ab-initio total energy calculations for metals and semiconductors using a planewave basis set. Comput. Mater. Sci. 1996, 6, 15-50.

(44) Perdew, J. P.; Burke, K.; Ernzerhof, M. Generalized Gradient Approximation Made Simple. Phys. Rev. Lett. 1996, 77, 38653868.

(45) Steinmann, S. N.; Corminboeuf, C. A generalizedgradient approximation exchange hole model for dispersion coefficients. J. Chem. Phys. 2011, 134, 44117.

(46) Steinmann, S. N.; Corminboeuf, C. Comprehensive Benchmarking of a Density-Dependent Dispersion Correction. J. Chem. Theory Comput. 2011, 7, 3567-3577.

(47) Kresse, G.; Joubert, D. From ultrasoft pseudopotentials to the projector augmented-wave method. Phys. Rev. B 1999, 59, 1758-1775.

(48) Karhánek, D.; Bučko, T.; Hafner, J. A density-functional study of the adsorption of methane-thiol on the (111) surfaces of the Ni-group metals: II. Vibrational spectroscopy. J. Phys. Condens. Matter. 2010, 22, 265006.

(49) Slater, J. C. Statistical Exchange-Correlation in the SelfConsistent Field. In Advances in Quantum Chemistry; Löwdin, P.-O., Ed.; Academic Press, 1972; pp 1-92.

(50) Janak, J. F. Proof that $\partial \mathrm{E} / \partial \mathrm{n}_{\mathrm{i}}=\varepsilon$ in density-functional theory. Phys. Rev. B 1978, 18, 7165-7168.

(51) Pueyo Bellafont, N.; Viñes, F.; Hieringer, W.; Illas, F. Predicting core level binding energies shifts: Suitability of the projector augmented wave approach as implemented in VASP. $J$. Comput. Chem. 2017, 38, 518-522.
(52) Ansari, R.; Malakpour, S.; Faghihnasiri, M.; Sahmani, S. An ab initio investigation into the elastic, structural and electronic properties of $\mathrm{MoS}_{2}$ nanotubes. Superlattice Microst. 2015, $82,188-200$.

(53) Chou, S. S.; Sai, N.; Lu, P.; Coker, E. N.; Liu, S.; Artyushkova, K.; Luk, T. S.; Kaehr, B.; Brinker, C. J. Understanding catalysis in a multiphasic two-dimensional transition metal dichalcogenide. Nat Commun 2015, 6, 141.

(54) C. Sourrisseau; R.Cavagnat; M. Fouassier, and P. Maraval. Electronic, vibrational and resonance Raman spectra of the layered semiconducting compound $\mathrm{NbS}_{3}$. J. Raman Spectro. 1990, 21, 337-349.

(55) Rijnsdorp, J.; Jellinek, F. The crystal structure of niobium trisulfide, $\mathrm{NbS}_{3}$. J. Solid State Chem. 1978, 25, 325-328.

(56) Schweiger, H.; Raybaud, P.; Kresse, G.; Toulhoat, H. Shape and Edge Sites Modifications of $\mathrm{MoS}_{2}$ Catalytic Nanoparticles Induced by Working Conditions: A Theoretical Study. Journal of Catalysis 2002, 207, 76-87.

(57) Lauritsen, J. V.; Kibsgaard, J.; Helveg, S.; Topsøe, H.; Clausen, B. S.; Lægsgaard, E.; Besenbacher, F. Size-dependent structure of $\mathrm{MoS}_{2}$ nanocrystals. Nature Nanotech 2007, 2, 53-58.

(58) Kan, M.; Wang, J. Y.; Li, X. W.; Zhang, S. H.; Li, Y. W.; Kawazoe, Y.; Sun, Q.; Jena, P. Structures and Phase Transition of a $\mathrm{MoS}_{2}$ Monolayer. J. Phys. Chem. C 2014, 118, 1515-1522.

(59) Huang, Q.; Li, X.; Sun, M.; Zhang, L.; Song, C.; Zhu, L.; Chen, P.; Xu, Z.; Wang, W.; Bai, X. The Mechanistic Insights into the $2 \mathrm{H}-1 \mathrm{~T}$ Phase Transition of $\mathrm{MoS}_{2}$ upon Alkali Metal Intercalation: From the Study of Dynamic Sodiation Processes of $\mathrm{MoS}_{2}$ Nanosheets. Adv. Mater. Interfaces 2017, 4, 1700171.

(6o) Zhu, J.; Wang, Z.; Yu, H.; Li, N.; Zhang, J.; Meng, J.; Liao, M.; Zhao, J.; Lu, X.; Du, L. et al. Argon Plasma Induced Phase Transition in Monolayer $\mathrm{MoS}_{2}$. J. Am. Chem. Soc. 2017, 139, 10216-10219.

(61) Huang, H. H.; Fan, X.; Singh, D. J.; Zheng, W. T. First principles study on $2 \mathrm{H}-1 \mathrm{~T}$ ' transition in $\mathrm{MoS}_{2}$ with copper. Phys. Chem. Chem. Phys. 2018, 20, 26986-26994.

(62) Oumahi, C.; Barros-Bouchet, M. I. de; Le Mogne, T.; Charrin, C.; Loridant, S.; Geantet, C.; Afanasiev, P.; Thiebaut, B. $\mathrm{MoS}_{2}$ formation induced by amorphous $\mathrm{MoS}_{3}$ species under lubricated friction. RSC Adv. 2018, 8, 25867-25872.

(63) Wang, Z. $2 \mathrm{H} \rightarrow 1 \mathrm{~T}^{\prime}$ phase transformation in Janus monolayer MoSSe and MoSTe: An efficient hole injection contact for ${ }_{2} \mathrm{H}_{-} \mathrm{MoS}_{2}$. J. Mater. Chem. C 2018, 6, 13000-13005.

(64) Jin, Q.; Liu, N.; Chen, B.; Mei, D. Mechanisms of Semiconducting $2 \mathrm{H}$ to Metallic $1 \mathrm{~T}$ Phase Transition in Twodimensional $\mathrm{MoS}_{2}$ Nanosheets. J. Phys. Chem. C 2018, 122, 2821528224.

(65) Xia, Z.; Tao, Y.; Pan, Z.; Shen, X. Enhanced photocatalytic performance and stability of $1 \mathrm{~T} \mathrm{MoS}_{2}$ transformed from $2 \mathrm{H} \mathrm{MoS}_{2}$ via Li intercalation. Results Phys. 2019, 12, 2218-2224. 


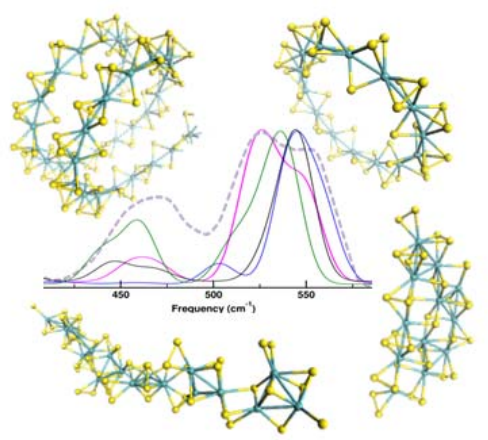

